\title{
Efficiency Assessment of Wind Power Resources in China's Six Regions
}

\author{
Xin Li ${ }^{1}$, Liu Chen ${ }^{1}$, Runbo Zhou ${ }^{1}$, Minxi Wang ${ }^{1 *}$ \\ 1 College of Management Science, Chengdu University of Technology, Chengdu 610051, China; \\ E-mail: lixin2012@cdut.cn; chenliusylvia@sina.com; zrbnxyc@163.com; \\ *Correspondence: wangminxi@ mail.cdut.edu.cn
}

\begin{abstract}
The purpose of this paper is to investigate the utilization efficiency and exploitation efficiency of wind power resources in China's six regions, then cites the idea of inputoutput ratio and builds an assessment method for calculating efficiency of wind power resources in 2016. The results obtained in this study include: a. The average utilization efficiency and exploitation efficiency of wind energy resources in China in 2016 are 0.8135 and 0.3631 respectively. b. Although "Three North" region has the most abundant wind energy resources, but its utilization efficiency is far lower than that of the East China and South China regions. c. The more economically developed regions, the higher efficiency utilization of wind energy resources. d. Most provinces have great exploitation potential, and provinces with high utilization efficiency and lower exploitation efficiency can be developed first. The findings of this study reveal current wind energy efficiency assessment in China and provide a reference for both energy practitioners and policy makers.
\end{abstract}

Keywords-Utilization efficiency; Exploitation efficiency; Input-output ratio; Wind power resources; China's six regions

\section{INTRODUCTION}

As the global energy crisis intensifies, more and more attention has been paid to the development of renewable energy. Wind energy is one of the most promising renewable energy resources due to its availability, low cost and relatively mature technologies. China is now the world's largest energy consumer, with cumulative installed capacity reached 44.73 GW by the end of 2010, exceeding the target set in China's long-term energy planning for 2020 [1]. China has abundant wind energy resources, and its theoretical reserve ranks first in the world [2]. It is mainly distributed in the "Three North" region, which is conducive to concentrated exploitation and utilization. Data Envelopment Analysis (DEA), is an evaluation method used to evaluate the input-output efficiency of decision-making units. It was developed by Charnes et al. [3], and it has been studied by a large number of researchers for various applications. Wang et al. [4] evaluate the effectiveness of wind power utilization of 25 provincial regions and six regional power grids in China for the years of 2014 and 2015 by using DEA and analyze its influential factors. Li et al. [5] reflect wind utilization efficiency from the five views of wind energy exploitation, energy-quality efficiency, technological level, power grid receptive ability, and wind energy consumption comprehensively. A two-stage data envelopment analysis model including DEA and Tobit regression is adopted to assess wind power efficiency in China and the United States

This research is supported by funding from Cultivating program of excellent innovation team of Chengdu University of Technology (KYTD201406), and Projects of the National Social Science Foundation of China (17BGL147), and Major projects of Sichuan Federation of Social Science Associations (2017).
[6-7]. Taking the Northeast China Grid as an example, Zhao et al. [8] argues there are two categories of constrained factors on the effective utilization of wind power, namely structural factor and operational factor. The perspective of wind energy utilization is presented, which focuses on seven wind power bases [9]. Behind the successful development of wind power, a series of challenges still exist in China [10]. Therefore, this paper uses the thought of input-output ratio to assess the efficiency of wind power, considering the availability of data and the status quo of China's wind power.

The remainder of this paper is organized as follows: Section 2 quotes the idea of input-output ratio and proposes a method for calculating the efficiency of wind energy resources. Section 3 demonstrates efficiency calculation results and corresponding discussions. At last, Section 4 provides a summary and policy suggestions for the future development of wind energy resources in China.

\section{METHODOLOGY}

In order to measure the utilization efficiency and exploitation efficiency of wind energy resources in the six regions of China, this paper adopts the method of input-output ratio. Each indicator represents a factor that affects the efficiency of wind energy resources, simultaneously describing with multiple indicators can reflect its overall characteristics more fully.

\section{A. Input indicators}

1) The total amount of wind energy resources that can be developed

Xue et al. [2] given the national and provincial wind energy reserves, of which the provincial wind energy in the calculation of "actual exploitable quantity" estimated by $1 / 10$ of the "theoretical exploitable quantity" of wind energy. However, comparing the data of "Development of Wind Power Industry in 2016" released by National Energy Administration shows that the accumulated installed capacity of wind power in partial provinces in 2016 has far exceeded the estimated actual developable volume given in [2]. Hence, this paper calculates the actual amount of wind energy resources can be developed in each province by taking the value of $3 / 10$ of "theoretical exploitable quantity" of wind energy in literature [2]. Its calculation as following:

$$
R_{i j}=0.785 \times R_{i j}^{\prime} \times \frac{3}{10}
$$


In equation (1), Rij epresents the actual amount of wind energy resources that can be developed in $\mathrm{i}$ province for $\mathrm{j}$ region, and $\mathrm{R}^{\prime} \mathrm{ij}$ represents the theoretical amount of wind energy resources can be developed in i province for $\mathrm{j}$ region. (Unit: $10^{7} \mathrm{~kW}$ )

2) Wind power cumulative installed capacity

The cumulative wind power grid capacity reflects the scale of wind farm construction and power generation capacity, and it can cover a lot of information. Therefore, the cumulative grid capacity of wind power as an important factor in input indicators. Hypothetically, $\mathrm{Cij}$ represents the cumulative installed capacity of wind power in $\mathrm{i}$ province for $\mathrm{j}$ region. (Unit: 104 kW)

\section{3) The number of hours that wind power available}

The number of hours that wind power can be exploited consists of two parts.

$$
H_{i j}=E_{i j}+F_{i j}
$$

In equation (2), Hij represents the number of hours that wind power available in i province for $\mathrm{j}$ region, Eij represents the actual hours of wind power utilization in $\mathrm{i}$ province for $\mathrm{j}$ region, and Fij represents the hours of equivalent utilization of abandoned wind power in i province for $\mathrm{j}$ region.(Unit: hours)

$$
F_{i j}=\frac{Q_{i j}}{C_{i j}}
$$

In equation (3), Qij represents the electricity of abandoned wind power in i province for $\mathrm{j}$ region (Unit: $108 \mathrm{~kW} \cdot \mathrm{h}$ ), and $\mathrm{Cij}$ represents the accumulative installed capacity of wind power in i province for $\mathrm{j}$ region (Unit: $104 \mathrm{~kW}$ ).

\section{B. Output indicator}

This paper selects wind power generation as the only output index. Taking the annual generation of wind power as output index can cover a lot of information and avoid the interference with linear relationship indexes. Hypothetically, Yij represents the wind power generation in i province for $\mathrm{j}$ region (Unit: 108 $\mathrm{kW} \cdot \mathrm{h})$.

\section{Efficiency assessment}

This paper estimates the utilization efficiency and exploitation efficiency of wind energy resources of six provinces in China based on the constructed input and output indicators of wind energy utilization efficiency, including 31 provinces (autonomous regions), and deeply analyzes their levels of efficiency. This paper presents the following formulas :

$$
P_{i j}=\frac{Y_{i j}}{C_{i j} \times H_{i j}}=\frac{Y_{i j}}{C_{i j} \times\left(E_{i j}+\frac{Q_{i j}}{C_{i j}}\right)}
$$

In formula (4), Pij means the utilization efficiency of wind power resources in $\mathrm{i}$ province for $\mathrm{j}$ region, and $\{(\mathrm{i}, \mathrm{j}) \mid \mathrm{i}=$ $1,2,3 \ldots \leq 6, \mathrm{j}=1,2,3,4,5,6\}$.

$$
\overline{P_{j}}=\frac{\sum_{i=1}^{n} P_{i j}}{n}
$$

In formula (5), $\bar{P}_{j}$ means the average utilization efficiency of wind energy resources in $\mathrm{j}$ region, and $\mathrm{n}$ means there are $\mathrm{n}$ provinces (autonomous regions) in $\mathrm{j}$ region.

$$
\bar{P}=\frac{1}{6} \sum_{j=1}^{m} \overline{P_{j}}
$$

In formula (6), $\bar{P}$ means the average utilization efficiency of wind energy resources in China, and m means there are six major regions in China divided by this paper.

$$
K_{i j}=\frac{C_{i j}}{R_{i j}}=\frac{C_{i j}}{0.785 \times R^{\prime}{ }_{i j} \times \frac{3}{10}}
$$

In formula (7), Kij means the exploitation efficiency of wind power resources in i province for $\mathrm{j}$ region, and $\{(\mathrm{i}, \mathrm{j}) \mid \mathrm{i}=$ $1,2,3 \ldots \leq 6, j=1,2,3,4,5,6 \quad\}$. The algorithm of average exploitation efficiency is the same as that of average utilization efficiency.

\section{Data sources}

This paper focus on six regions of China include 22 provinces, 4 municipalities, 5 autonomous regions (Taiwan, Macao and Hong Kong are excluded due to the lack of relevant data). The cumulative installed capacity and actual hours of wind power utilization come from the "Development Status of National Wind Power Industry". In addition, the amount of abandon wind power and annual wind power generation are from the National Energy Administration and China Statistical Yearbook. Provincial GDP Rankings in 2016 are from Statistics Bulletin.

\section{RESULTS AND DISCUSSION}

\section{A. Results}

According to the original data, combined with the formula (1) to (7) in the methodology, we can calculate the exploitation efficiency and utilization efficiency of the wind energy resources in China's six regions. Due to a shortage of data on abandoned wind power, part of the efficiency values are not taken into account when calculating utilization efficiency.

The efficiency values of wind energy resource in China's six regions in 2016 are shown in Table 1 to Table 7: 
TABLE I THE EFFICIENCY VALUES OF WIND ENERGY RESOURCE IN NORTHEAST REGION IN 2016

\begin{tabular}{|c|c|c|}
\hline $\begin{array}{c}\text { Northeast } \\
\text { region }\end{array}$ & $\begin{array}{c}\text { Utilization } \\
\text { efficiency }\end{array}$ & $\begin{array}{c}\text { Exploitation } \\
\text { efficiency }\end{array}$ \\
\hline Heilongjiang & 0.7758 & 0.1085 \\
\hline Jilin & 0.6957 & 0.2640 \\
\hline Liaoning & 0.8429 & 0.3825 \\
\hline Average efficiency & 0.7715 & 0.2517 \\
\hline
\end{tabular}

TABLE II THE EFFICIENCY VALUES OF WIND ENERGY RESOURCE IN NORTH CHINA REGION IN 2016

\begin{tabular}{|c|c|c|}
\hline $\begin{array}{c}\text { North China } \\
\text { region }\end{array}$ & Utilization efficiency & Exploitation efficiency \\
\hline Hebei (include Beijing and Tianjin) & 0.8180 & 0.6734 \\
\hline Shandong & 0.9374 & 0.7105 \\
\hline Shanxi & 0.8269 & 0.6640 \\
\hline Inner Mongolia & 0.7839 & 0.1380 \\
\hline Average efficiency & 0.8416 & 0.5465 \\
\hline
\end{tabular}

TABLE III THE EFFICIENCY VALUES OF WIND ENERGY RESOURCE IN NORTHWEST REGION IN 2016

\begin{tabular}{|c|c|c|}
\hline $\begin{array}{c}\text { Northwest } \\
\text { region }\end{array}$ & Utilization efficiency & Exploitation efficiency \\
\hline Shaanxi & 0.5537 & 0.3543 \\
\hline Gansu & 0.5598 & 0.3724 \\
\hline Ningxia & 0.7804 & 1.0000 \\
\hline Qinghai & 0.8397 & 0.0095 \\
\hline Xinjiang & 0.6009 & 0.1724 \\
\hline Tibet & 0.5241 & 0.0001 \\
\hline Average efficiency & 0.6431 & 0.3181 \\
\hline
\end{tabular}

TABLE IV THE EFFICIENCY VALUES OF WIND ENERGY RESOURCE IN EAST CHINA REGION IN 2016

\begin{tabular}{|c|c|c|}
\hline $\begin{array}{c}\text { East China } \\
\text { region }\end{array}$ & Utilization efficiency & Exploitation efficiency \\
\hline Jiangsu (include Shanghai) & 0.8557 & 0.5444 \\
\hline Zhejiang & 0.8944 & 0.2426 \\
\hline Anhui & 0.9108 & 0.2355 \\
\hline Fujian & 0.9335 & 0.5200 \\
\hline Average efficiency & 0.8986 & 0.3856 \\
\hline
\end{tabular}

TABLE V THE EFFICIENCY VALUES OF WIND ENERGY RESOURCE IN CENTRAL CHINA REGION IN 2016

\begin{tabular}{|c|c|c|}
\hline $\begin{array}{c}\text { Central China } \\
\text { region }\end{array}$ & Utilization efficiency & Exploitation efficiency \\
\hline Henan & 0.9100 & 0.0943 \\
\hline Jiangxi & 0.8322 & 0.1229 \\
\hline Hubei & 0.8441 & 0.3476 \\
\hline Hunan & 0.8458 & 0.2934 \\
\hline Sichuan (include Chongqing) & 0.7563 & 0.1170 \\
\hline Average efficiency & 0.8377 & 0.1950 \\
\hline
\end{tabular}


TABLE VI THE EFFICIENCY VALUES OF WIND ENERGY RESOURCE IN SOUTHERN REGION IN 2016

\begin{tabular}{|c|c|c|}
\hline $\begin{array}{c}\text { Southern } \\
\text { region }\end{array}$ & Utilization efficiency & Exploitation efficiency \\
\hline Guangdong & 0.9896 & 0.4580 \\
\hline Guangxi & 0.8204 & 0.1329 \\
\hline Yunnan & 0.8716 & 0.6701 \\
\hline Guizhou & 0.8413 & 1.0000 \\
\hline Hainan & 0.9201 & 0.1615 \\
\hline Average efficiency & 0.8886 & 0.4845 \\
\hline
\end{tabular}

TABLE VII THE AVERAGE EFFICIENCY VALUES OF WIND ENERGY RESOURCE IN CHINA IN 2016

\begin{tabular}{|c|c|c|}
\hline & Utilization efficiency $(\bar{P})$ & Exploitation efficiency $(\bar{K})$ \\
\hline $\begin{array}{c}\text { The national average } \\
\text { efficiency }\end{array}$ & 0.8135 & 0.3631 \\
\hline
\end{tabular}

\section{B. Efficiency analysis}

Efficiency scores calculated by the method are strongly influenced by input/output variables. The evaluation results of the six regions take the average of provincial efficiency scores in the six regions, which can more directly show the differences in utilization efficiency and exploitation efficiency of the overall wind energy resources. From Table 1 to Table 7, the evaluation results show that the efficiency of wind energy resources in China's six regions has the following characteristics:

\section{1) From the perspective of utilization efficiency}

a) In 2016, wind energy utilization efficiency was highest in the East China region, and that in the northwest region was the lowest. The utilization efficiency of more than 0.9 was mostly located in the East China and South China regions, and those below 0.8 were all located in the "Three North" region. Although the wind power resources in the "Three North" region are the most abundant, the cumulative installed capacity is much higher than the other three regions, which accounts for a large proportion of the total installed capacity of wind power in the country. This shows that the "Three North" region has obvious advantages in scale effect. But, the utilization efficiency of wind energy resources in the "Three North" region is generally lower than the average level. The "Three North" region is far from the load center, and it is inferior to the East China and South China regions in terms of power supply structure, power grid structure, and peak load adjustment capability, and the outbound channels are poor, resulting in much lower utilization efficiency of wind energy resources than in East China and South China regions. b) In the "Three North" region of China, the utilization of wind energy resources in economically developed provinces is relatively efficient. For example, Shandong, Hebei, and Liaoning Province ranked third, eighth, and fourteenth respectively in the national GDP rankings in 2016, and other provinces in the "Three North" region were all after the 15 th. The more economically developed regions, the better the level of grid operation, the stronger capacity of wind power consumption, and the more efficient utilization of wind energy resources.

\section{2) From the perspective of exploitation efficiency}

a) The theoretically exploitable amount of wind energy resources in this paper only reflects the amount of wind energy resources at a height of 10 meters above the ground and does not include the amount of wind resources on the sea surface. In 2016, the wind energy exploitation efficiency in North China was the highest, and that in Central China was the lowest. China's energy sector has successively issued a number of measures to improve the phenomenon of "wind power curtailment", but these measures only increase the utilization efficiency of wind energy resources. The utilization efficiency in the East China region is the highest, but the exploitation efficiency is not high, which leads to large-scale waste of wind power resources that can be developed but not yet developed.

b) The restrictions on resource endowments, geographical features, and population density of the areas in East, Central and South China regions have led to higher wind power exploitation costs. Therefore, compared to the "Three North" region, the scale of their investment is greatly insufficient. Most regions still have great potential for exploitation, and provinces with high utilization efficiency and lower exploitation efficiency can be developed first. 


\section{CONCLUSION AND POLICY RECOMMENDATIONS}

Along with the rapid development of wind power in China, the high efficient exploitation and utilization of wind energy resources is one of the important measures to achieve green development and energy conservation and emission reduction in China. We used the idea of input-output efficiency and built a calculative assessment method. Taking the 2016 data as an example to calculate efficiency of wind energy resources and then analyze the calculated results.

In order to further promote wind power development in China, we provide the following policy recommendations: (1) Northeast, North China, and Northwest regions should give priority to improving the utilization efficiency under the premise of maintaining and expanding the scale advantages. In Central China, East China, and South China regions, priority should be given to accelerating the investment scale of wind energy resources and improving exploitation efficiency while maintaining and improving utilization efficiency. (2) Due to the low utilization efficiency of wind energy resources in the "Three North" region with abundant wind energy resources in China, large amounts of wind energy resources are wasted. Therefore, in the short term, we can accelerate the construction of outbound channels, and in the long term we can promote economic development in the region, improve load characteristics and so on. (3) The "Three North" region should improve the structure of its power supply, establish a wind power supply trading mechanism and trading platform as soon as possible, and improve its ability to absorb on the spot. At the same time, it can release the capacity of cogeneration units and increase the peak shaving capacity in these areas. (4) Most provinces in China should increase the investment in the use of wind energy resources in a scientific and orderly manner, expand the utilization scale of wind energy resources, increase the cumulative installed capacity of wind power, exert scale effects and increase the overall utilization level of wind energy resources.

\section{REFERENCES}

[1] Kang J, Yuan J, Hu Z, Xu Y. Review on wind power development and relevant policies in China during the 11th Five-Year-Plan period. Renewable and Sustainable Energy Reviews 2012; 16(4):1907-15.

[2] Xue Y, Zhu R, Yang Z, Yuan C. Estimation of China's Wind Resource Storage. Acta Energiae Sclaris Sinica 2001;22(2):167-170.(In Chinese)

[3] Charnes A, Cooper WW, Rhodes E. Measuring the efficiency of decision making units. Eur Oper Res 1978; 2(6):429-44.

[4] Wang Y, Li Y, Wang D, Liu S. Evaluation of Wind Energy Resource Utilization Efficiency Based on DEA Model. Science and Technology Management Research 2017. (In Chinese)

[5] Wang Y, Li Y, Liu D, Liu S. Evaluation of Wind Energy Resource Utilization Efficiency Based on Improved Grey Target Theory. Science and Technology Management Research 2017. (In Chinese)

[6] Wu Y, Hu Y, Xiao X, Mao C. Efficiency assessment of wind farms in China using two-stage data envelopment analysis. Energy Conversion and Management 2016; 123: 46-55.

[7] Saglam U. A two-stage data envelopment analysis model for efficiency assessments of 39 state's wind power in the United States. Energy Conversion and Management 2017; 146: 52-67.

[8] Zhao X, Zhang S, Yang R, Wang M. Constraints on the effective utilization of wind power in China: An illustration from the northeast China grid. Renewable and Sustainable Energy Reviews 2012; 16(7): 4508-4514.

[9] $\mathrm{Yu}$ L, Xu C. Exploitation and utilization of the wind power and its perspective in China. Renewable and Sustainable Energy Reviews 2012; 16 (4):2111-2117.

[10] Yu X, Qu H. Wind power in China-Opportunity goes with challenge. Renewable and Sustainable Energy Reviews 2010; 14(8):2232-7. 